\title{
Ser ou não ser sustentável, eis a questão! Um olhar sobre a relação da pesquisa em turismo e a panaceia do sustentável ${ }^{1}$
}

\section{Resumo}

Sandra Dalila Corbari Marina Rossi Ferreirab

A busca pelo crescimento econômico, mascarado por um ideal de desenvolvimento, acarretou em diversos problemas, principalmente no âmbito ambiental. 0 alerta sobre a má utilização dos recursos e a impossibilidade de um crescimento perpétuo culminou na busca por alternativas dentro do modelo vigente, como é o caso da noção de desenvolvimento sustentável, amplamente utilizada em várias esferas, incluindo a acadêmica e a governamental. No turismo, várias pesquisas são publicadas anualmente, utilizando-se da ideia de sustentabilidade, desenvolvimento sustentável no turismo e do turismo sustentável. No entanto, o termo "desenvolvimento sustentável" foi - e continua sendo - utilizado em diversos casos de forma indiscriminada e sem a devida reflexão sobre seu significado e viabilidade. Destarte, o presente ensaio teórico buscou delinear questões para reflexão a respeito da forma como o campo do turismo tem se apropriado de termos e ideias que, por vezes, são inviáveis e, por outras, são contraditórias. Ademais, em alguns casos, nota-se que o turismo tem se isentado do debate a respeito e de sua responsabilidade por ações que podem ser consideradas contrárias aos ideais da sustentabilidade.

Palavras-chave: Desenvolvimento; Sustentabilidade; Desenvolvimento Sustentável; Turismo.

\section{Abstract \\ To be or not to be sustainable, that is the question! A look at the relationship of tourism research and the panacea of sustainable}

The search for economic growth, masked by an ideal of development, has led to several problems, mainly in the environmental sphere. The warning about the misuse of resources and the impossibility of perpetual growth culminated in the search for alternatives within the current model, as is the case of the understanding of sustainable development, widely used in several spheres, including academic and governmental. In tourism, several surveys are published annually, using the idea of sustainability, sustainable development in tourism and sustainable tourism. However, the term "sustainable development" has been - and continues to be - used in many cases indiscriminately and without due reflection on its meaning and viability. Thus, the present theoretical essay sought to delineate questions for reflection on the way in which the field of tourism has appropriated terms and ideas that are sometimes unfeasible and, for others, are contradictory. In addition, in some cases, tourism has been exempted from the debate about it and responsibility for actions that may be considered contrary to the ideals of sustainability.

Keywords: Development; Sustainability; Sustainable development; Tourism.

1. Esta pesquisa se viabilizou graças a bolsas concedidas pela Coordenação de Aperfeiçoamento de Pessoal de Nível Superior (CAPES) e pelo Conselho Nacional de Desenvolvimento Científico e Tecnológico (CNPq).

a. Doutora em Meio Ambiente e Desenvolvimento pela Universidade Federal do Paraná, Curitiba, Paraná, Brasil. E-mail: corbari91@hotmail.com

b. Doutoranda em Geografia pela Universidade Federal do Paraná, Curitiba, Paraná, Brasil. E-mail: lizmarina.ferreira@gmail.com 


\section{Resumen}

iSer o no ser sostenible, he aquí la cuestión! Una mirada hacia la relación de la investigación en turismo y la panacea del sostenible

La búsqueda del crecimiento económico, ocultado por la noción de desarrollo, acarreó diversos problemas, principalmente en el ámbito ambiental. La alerta sobre la mala utilización de los recursos y la imposibilidad de un crecimiento perpetuo culminó en la búsqueda de alternativas dentro del modelo vigente, como es el caso del desarrollo sostenible, noción ampliamente utilizada en varios ámbitos, incluyendo en el científico y gubernamental. En el turismo, todos los años son publicados resultados de investigaciones que se utilizan de la idea de sostenibilidad, del desarrollo sostenible, del desarrollo sostenible en el turismo y del turismo sostenible. Sin embargo, el término "desarrollo sostenible" fue - y sigue siendo - utilizado de forma indiscriminada y sin la debida reflexión sobre su significado y viabilidad. De este modo, el presente ensayo teórico buscó delinear cuestiones para reflexionar acerca de cómo el campo del turismo se ha apropiado de términos e ideas que, a veces, son inviables y, por otras, son contradictorias. Además, en algunos casos, el turismo se ha eximido del debate al respecto del desarrollo sostenible o de su responsabilidad por acciones que pueden ser consideradas contrarias a los ideales de la sostenibilidad.

Palabras clave: Desarrollo; Sostenibilidad; Desarrollo sostenible; Turismo.

\section{INTRODUÇÃo}

A constante busca pelo crescimento econômico, mascarado pelo termo "desenvolvimento", vem gerando problemas no mundo todo. Países passaram a ser classificados em desenvolvidos e subdesenvolvidos, esses últimos buscando alcançar o mesmo nível tecnológico e industrial dos primeiros. Com isso, o mundo passou a vivenciar um desenvolvimento ecologicamente suicida, socialmente perverso, politicamente injusto, eticamente censurável e culturalmente alienado (Guimarães \& Bezerra, 2011).

No entanto, essa perspectiva de se pensar o desenvolvimento a partir da hierarquização dos países com base no estágio de seu avanço tecnológico já vem sendo questionada há décadas. Tem-se de um lado os denominados "desenvolvimentos alternativos", diferentes opções de retificação, reparação ou modificação do modelo de desenvolvimento hegemônico, mas que aceitam suas bases conceituais, Para Latouche (2007), basicamente, foram agregados "sobrenomes" ao termo desenvolvimento, como é o caso do "desenvolvimento sustentável".

Por outro lado, emergiram as "alternativas ao desenvolvimento", que apontam para geração de outros marcos conceituais, de modo a explorar ordenamentos sociais, econômicos e políticos diferentes dos que vendo sendo chamado "desenvolvimento" e que vão além da ideia de progresso e de modernidade (Gudynas, 2012).

0 presente ensaio teórico se ateve à primeira categoria, os desenvolvimentos alternativos, mais especificamente no desenvolvimento sustentável, derivado do termo de "sustentabilidade" e disseminado após a publicação do Relatório Brundtland, em 1987 (Organização das Nações Unidades [ONU], 1987). A abordagem leva em consideração o fato que os termos citados, utilizado "ad nauseam" (Diegues, 1992), foram apropriados pelo turismo.

Embora a noção de desenvolvimento sustentável tenha surgido tendo como base novos ideais, buscando encontrar uma alternativa à busca desenfreada 
pelo crescimento econômico e exploração da natureza, há autores que chamam a atenção à forma como o crescimento econômico foi incorporado e estimulado por esses novos discursos (Gudynas, 2012; Hoeffel \& Reis, 2011).

Com base neste contexto, o presente ensaio teórico teve como objetivo apontar e discutir criticamente o modo como o turismo tem se apropriado da noção de sustentabilidade e de desenvolvimento sustentável muitas vezes utilizando-os de modo genérico, sem aprofundar seus significados e implicações, e refletir sobre o quão "sustentável" a atividade turística realmente pode ser, visto que sua estruturação está sob um modelo hegemônico.

Desse modo, na sequência, são apresentadas diferentes compreensões sobre desenvolvimento e sua relação com o crescimento econômico. Em seguida, aborda-se a noção de sustentabilidade e desenvolvimento sustentável e a problemática relacionada a este. Após isso, adentra-se no debate sobre o desenvolvimento sustentável no turismo, além de explanar sobre o turismo sustentável trazendo exemplos do uso desse termo. Ao final, tem-se as considerações finais.

\section{A PROBlemÁtica-CHAVE: desenvolvimento Versus CRESCIMENTO ECONÔMICO}

Segundo os modelos da economia clássica, o crescimento econômico tem como propulsor a industrialização. Layrargues (1997) destaca que a percepção inicial de desenvolvimento surge dessa sucessão "evolutiva" de estágios. Baseada na noção de progresso, teria como objetivo colocar os países com economia baseada na agricultura no mesmo patamar que os que têm a economia baseada na indústria (Diegues, 1992), estando os Estados Unidos no ápice dessa "evolução" (Layrargues, 1997).

No entanto, ainda que no âmbito do sistema econômico capitalista, "crescimento econômico" e "desenvolvimento" sejam tratados como equivalentes, é preciso distingui-los. Ao longo do tempo, as teorias econômicas adaptaram seus discursos a respeito da utilização da natureza para geração de capital, emparelhando a uma noção de "desenvolvimento" (Corbari, 2017).

Não obstante, a diferença estrutural entre as noções citadas é que, enquanto a primeira é sinônimo de aumento ou expansão, maximizando a riqueza econômica, a segunda refere-se à mudança e evolução, exigindo que se evite a competitividade autodestrutiva, que se baseia na depreciação da força de trabalho e dos recursos naturais (Sachs, 2008; Cavalcanti, 2012).

Para Sachs (2008) o desenvolvimento deve levar à reparação de desigualdades históricas, diminuindo o abismo entre as antigas nações e a periferia colonial, entre a minoria modernizada e abastada economicamente e a maioria proletária, tida como "atrasada". Nesse sentido, o desenvolvimento se diferencia do crescimento econômico ao se propor ir além da mera multiplicação da riqueza material, a compreendendo como uma condição necessária, mas de forma alguma suficiente para se alcançar coletivamente uma melhor qualidade de vida (Sachs, 2008). Seria, assim, um conceito que transcende a perspectiva econômica, entendendo que todas as dimensões existentes são tão importantes quanto.

Diegues (1992) destaca que os enfoques podem ser reduzidos a três: desenvolvimento como sinônimo de crescimento econômico; desenvolvimento como 
etapas que os países subdesenvolvidos ou em desenvolvimento precisam atravessar; e desenvolvimento como processos de mudanças estruturais, implicando mudanças sociais e políticas estruturais. Esses modelos têm em comum a crença na industrialização como um motor do desenvolvimento.

O terceiro enfoque apontado por Diegues (1992) vai ao encontro da perspectiva de "alternativa ao desenvolvimento", que apontam para geração de outros marcos conceituais de modo a explorar ordenamentos sociais, econômicos e políticos diferentes dos que vem sendo chamado "desenvolvimento". Indo além do progresso e da modernidade (Gudynas, 2012), como por exemplo, a convivencialidade, a crítica feminista, a economia do cuidado, parte do decrescimento, pluralismo, interculturalismo, cidadanias expandidas, ecologia profunda e algumas manifestações do buen vivir. Alternativas que visam uma consolidação de modelos mais adequados a cada contexto social, cultural, ambiental e político.

Esse termo se diferencia dos "desenvolvimentos alternativos", que segundo Gudynas (2012) dizem respeito a diferentes opções de retificação, reparação ou modificação do desenvolvimento contemporâneo. Aceitando suas bases conceituais, tais como o crescimento contínuo ou a apropriação da natureza, e a discussão se atem à instrumentalização desse processo.

Gudynas (2012) destaca que os modelos alternativos são insuficientes para resolver os atuais problemas sociais e ambientais, tanto localmente quanto em escala global, uma vez que não os resolvem de fato. Desse modo, para o contexto latino-americano, por exemplo, se fazem necessárias "alternativas ao desenvolvimento".

Essa perspectiva se assemelha a de Latouche (2007), que ao categorizar dois posicionamentos a respeito do desenvolvimento (os que buscam "salvar" os pontos positivos do conceito e os que argumentam que se faz necessário rejeitá-lo), se posiciona favorável ao abandono dessa noção. Um dos argumentos desse autor é que o significado na teoria não condiz com a prática. Enquanto o discurso sobre o desenvolvimento aborda e defende que o mesmo produz melhorias para a sociedade, bem-estar, direitos, entre outros benefícios, na prática, implica em dominação exterior, desigualdades, rompimento com as raízes, entre outros.

Conforme destacado por Latouche (2007), vivencia-se a era do desenvolvimento "em partículas". Ao se cunhar termos como desenvolvimento sustentável, autocentrado, endógeno, participativo, comunitário, integrado, autônomo, local, ou de outras nomenclaturas como etnodesenvolvimento, microdesenvolvimento, entre outros, foram apenas designados "sobrenomes" que incorporam um componente social, cultural ou ecológico ao crescimento econômico.

Embora se reconheça a importância do debate a respeito dessas e outras perspectivas, como a decolonialidade, o presente ensaio não se aterá a elas, uma vez que neste momento o intuito é incitar a reflexão a respeito do desenvolvimento sustentável, escolhida dentre as "partículas" do desenvolvimento, por conta da sua ampla utilização no turismo.

\section{SUSTENTABILIDADE E DESENVOLVIMENTO SUSTENTÁVEL}

0 termo "sustentabilidade" provém das ciências agrobiológicas e se refere à capacidade de um sistema manter sua produtividade frente às perturbações (Estades, 1999). Tornou-se fortemente associado à esfera ambiental, 
principalmente porque na década de 1980 os conservacionistas e ecologistas a adotaram, fazendo alusão aos sistemas naturais e seguindo critérios ecológicos. Naquele momento era entendida como a possibilidade de se continuar a extrair "recursos" ambientais, desde que isso fosse feito respeitando as taxas de renovação e reprodução (Estades, 1999; Rodrigues, 2006; Gudynas, 2012).

Na sequência, a noção de sustentabilidade incorporou critérios econômicos, sociais e culturais, pressupondo diversas dimensões que se relacionam entre si (Estades, 1999). Para Rodrigues (2006) a sustentabilidade se tornou equivalente à ideia de um mundo melhor, com um caráter aparentemente neutro, acrítico e acima de interesses políticos ou de classe. Um item essencial no discurso político moderno, utilizada por muitas, se não a maior parte das empresas e partidos políticos. E não apenas isso, foi inserida em discussões e no cotidiano de diferentes esferas sociais, sendo aplicada nos mais diversos contextos (Limonad, 2013), levando ao amplo uso em um "sentido sem sentido", de forma anódina.

Destarte, a sustentabilidade se caracteriza como polissêmica, sendo apropriada e assumindo características específicas em argumentos mais politizados e outros mais adequados aos interesses do capital. Portanto é representada em um continuum entre a forma mais radical à mais conservadora, posturas mais revolucionárias e posturas de mudanças graduais (Hoeffel \& Reis, 2011), estando o desenvolvimento sustentável enquadrado nesta última.

Os debates sobre as possibilidades e os limites da expansão econômica estão presentes desde as primeiras reflexões e proposições sobre um futuro global mais sustentável. Em 1972, durante a Conferência Mundial das Nações Unidas sobre o Meio Ambiente, em Estocolmo, o Clube de Roma encomendou ao Massachusetts Institute of Technology (MIT) um informe denominado The Limits to Growth (Os Limites do Crescimento), com características catastrofistas, expondo a proposta de crescimento - populacional e econômico - zero, alegando que o crescimento perpétuo seria impossível (Gudynas, 2012; Rodrigues, 2006).

Anos mais tarde, em 1987, foi lançado o Relatório Brundtland, também denominado Our Common Future (Nosso Futuro Comum), redigido pela Comissão Mundial sobre Meio Ambiente e Desenvolvimento. Essa publicação lançou mundialmente a noção de desenvolvimento sustentável, representando a garantia das necessidades do presente sem comprometer a capacidade das gerações futuras atenderem às suas.

Na compreensão da Organização das Nações Unidas (ONU) (1987), o desenvolvimento sustentável contém dois conceitos-chave: 1) o de "necessidades", sobretudo o que eles chamam de necessidades essenciais dos pobres, que devem receber máxima prioridade (como a fome, por exemplo); e 2) o de limitações que o estágio da tecnologia e organização social impõe ao meio, impedindo-o de atender às demandas do presente e do futuro.

Para o primeiro conceito-chave, o relatório expõe só ser possível caso haja "crescimento potencial pleno", ou seja, é preciso que o crescimento econômico chegue às regiões onde as necessidades em questão não estão sendo atendidas. Já nas regiões onde as necessidades foram atendidas, há compatibilidade com o crescimento econômico, com a ressalva de que seja dentro do paradigma da sustentabilidade e pautado na não-exploração de outrem (Organização das Nações Unidades [ONU], 1987).

Com esta breve exposição de trechos destes documentos é possível compreender, que o crescimento econômico não era apenas aceito, como incentivado 
desde a perspectiva do Relatório Brundtland. No entanto, como destacado por Gudynas (2012, p. 30) "se vuelve a sostener que el desarrollo implica crecimiento económico, y para lograr eso, la conservación de los recursos naturales pasa a ser una condición necesaria".

Estudiosos - dentre eles Gudynas (2012) - defendem que a noção de desenvolvimento econômico implícita no relatório supracitado seria propositalmente indefinida e fluida, permitindo uma pluralidade de leituras, desde um sentido associado à justiça socioambiental e ética até uma perspectiva conservadora de crescimento econômico (Hoeffel \& Reis, 2011). Cabe salientar que o desenvolvimento sustentável é lançado na arena política em uma fase de hegemonia neoliberal (Rodrigues, 2006).

Assim, o desenvolvimento sustentável permitiu definitivamente a gestão ambiental empresarial e governamental, uma vez que superava o estigma causado pelo informe "Nosso futuro comum" e coloca o crescimento econômico como imprescindível para resolver os problemas que cria (Estades, 1999). 0 fato é que o conceito foi generalizado nos debates acadêmicos, assim como no âmbito das políticas públicas. Diegues (1992, p. 22) destacou que o termo acabou sendo usado "ad nauseam", sobretudo em discursos governamentais.

Se analisada de forma aprofundada, concorda-se com o economista brasileiro Clóvis Cavalcanti (2012), que defende que o desenvolvimento por si só é sustentável, pois, se é insustentável está fadado a acabar e, portanto, não é desenvolvimento, mas um "espasmo" da sociedade. Assim como Diegues (1992) defende, seria necessário analisar o "sustentável" para além do adjetivo, mas adentrando ao conteúdo da proposta.

Nesse aspecto, há que considerar que a perspectiva da sustentabilidade e de transição para um regime internacional sobre o meio ambiente aponta para uma mudança profunda no padrão de civilização, em particular no que se refere ao seu padrão ecocultural que caracteriza a relação do ser humano com a natureza (Guimarães \& Bezerra, 2011). Ou seja, o que deve mudar é o modo como a humanidade se relaciona com a parte não humana da natureza.

Para Limonad (2013), ao impor dialeticamente limites à reprodução capitalista, a questão ambiental é capaz de evidenciar contradições entre os interesses sociais e privados, entre dinâmicas de reprodução social e de acúmulo de capital. Isso porque, segundo a autora, a questão ambiental impõe tais limites em nome da preservação do meio ambiente, seja pensando nas futuras gerações ou como forma de reserva de valor para reprodução do próprio capitalismo.

Nesta perspectiva, a desconstrução da questão ambiental contribui para explicitar seu caráter geopolítico e estratégico para a reprodução do capitalismo, bem como evidencia "numerosos mitos relativos ao progresso tecnológico, à eficiência econômica e ao crescimento sem riscos" (Milani, 2008, p. 292).

Cabe ressaltar que a ideia da sustentabilidade continua fortemente associada indiscriminadamente à questão ambiental, o que contribui para "jogar uma cortina de fumaça sobre estas contradições, pois não propõe alterações nos modos de produzir e de pensar do modelo dominante" (Rodrigues, 1998, p. 57). Além disso, diferentes atores sociais e agentes, incluindo estudiosos e tomadores de decisão, defendem a sustentabilidade, adotando-a como uma mera síntese de uma sensibilidade ambiental (Limonad, 2013).

Posto isto, destaca-se a necessidade de não apenas pensar um novo paradigma, mas também considerar a existência de várias categorias de sociedade 
sustentável, ancoradas em seus modos particulares de vida (Diegues, 1992). Esse autor ressalta que esses novos paradigmas precisam considerar à existência de grande diversidade ecológica, biológica e cultural entre os povos, que mesmo com a pressão do modelo ocidental capitalista não deixaram de existir.

\section{DO TURISMO SUSTENTÁVEL AO DESENVOLVIMENTO SUSTENTÁVEL NO TURISMO}

Richard Butler (1999) ao redigir o artigo Sustainable tourism: a state-of-the-art informou que alguns colegas sugeriram que uma discussão sobre definições de desenvolvimento sustentável não era necessária, uma vez que seu significado era claro, sendo mais importante o foco na forma de sua aplicação. 0 autor destaca que, embora tenha inicialmente concordado, um exame aprofundado da literatura o fez repensar a discussão sobre o tema, não por não haver uma definição, mas pela existência de inúmeras. Assim, constatou que o termo que foi utilizado de modo incessante tornou-se uma forma de ideologia, um slogan político e até mesmo uma filosofia, um processo ou um produto.

No decorrer do tempo, multiplicaram-se as práticas ditas sustentáveis, incluindo atividades de turismo, gestão de espaços, bem como de cidades sustentáveis. Assim como o discurso político se adequou à ideia da sustentabilidade, o turismo também se adaptou e com isso, gerou-se a ideia de "turismo sustentável" (Mowforth \& Munt, 2009).

No âmbito brasileiro a situação se repete. 0 uso dos termos "sustentável" e "sustentabilidade" na pesquisa sobre o turismo é expressiva. Um levantamento realizado no banco de dados Publicações em Turismo, indica 719 resultados para presença do termo "sustentável" e 616 resultados para "sustentabilidade".

Ao consultar os termos citados acima, em documentos inseridos no banco de dados do Portal de Periódicos da Coordenação de Aperfeiçoamento de Pessoal de Nivel Superior (Capes, s.d.), verificou-se que 5.030 documentos tinham "sustentabilidade" (abrangendo o período de 1969 a 2019) e 4.410 tinham "sustentável" em seu título ou assunto (abrangendo o período de 1990 a 2019).

Na busca conjunta com o termo "turismo", o resultado foi 142 documentos, publicados entre 1998 e 2019 sobre "sustentabilidade e turismo" (representando $2,82 \%$ do total dos artigos com o termo "sustentabilidade"). A busca combinada entre "sustentável" e "turismo" por sua vez gerou um total de 195 documentos, publicados entre 2002 e 2019 (representando 4,42\% do total dos documentos). Embora seja necessária uma pesquisa analisando o conteúdo dos documentos, o resultado deste levantamento já demonstra a expressividade desses termos nas pesquisas sobre o turismo no Brasil, atestando a necessidade de um olhar mais atento sobre a forma como eles vêm sendo apropriados por pesquisadores.

Sobre o amplo uso do termo, Butler (1999) destacou que é improvável que exista uma definição totalmente aceita e que seja universalmente aplicada, de modo a se tornar interessante para todas as partes. No caso do turismo, o resultado foi a adoção generalizada, geralmente sem qualquer tipo de definição, pressupondo uma compreensão já existente sobre o conceito. 0 fato é que, assim como apontado por Irving, Bursztyn, Sancho e Melo (2005), ao se apropriar do termo, o discurso 
tende a privilegiar o "sustentável" da mesma forma em que o pulveriza, tornando-o tão amplo e genérico que se transforma numa utopia contemporânea.

Mowforth \& Munt (2009) afirmam a necessidade de politizar o debate no turismo, já que uma vez que se isso não ocorre, a sustentabilidade continuará a ser utilizada pelo modelo hegemônico e estará cada vez mais a serviço dos controladores do capital, grandes empresas transnacionais e outras organizações que gerenciam o setor. Se não foram politizados, novos segmentos e novas formas de se praticar o turismo, embora pareçam ser contra hegemônicas, podem contribuir para a manutenção da desigualdade de poder existente no setor.

A definição mais aceita e usada é a da Organização Mundial do Turismo (OMT) (s.d.) que o conceitua como "el turismo que tiene plenamente en cuenta las repercusiones actuales y futuras, económicas, sociales y medioambientales para satisfacer las necesidades de los visitantes, de la industria, del entorno y de las comunidades anfitrionas". É possível verificar que se assemelha à noção de desenvolvimento sustentável ao entender a necessidade do uso ótimo dos recursos para satisfazer as necessidades presentes, sem comprometer a possibilidade de satisfação das gerações futuras.

Ademais, aponta que as necessidades dos visitantes, do mercado, do entorno e das comunidades anfitriãs devem ser satisfeitas de forma igualitária, principalmente no que diz respeito à geração e distribuição de renda, perspectiva com a qual não se concorda, uma vez que se entende que é preciso priorizar as necessidades e os objetivos das comunidades receptoras. Inclusive fomentando a autodeterminação, a autonomia de escolha sobre suas formas de obtenção de renda e a autogestão, especialmente em comunidades tradicionais e indígenas. Isso implica compreender que a comunidade deve ter autonomia para escolher o modelo de turismo que almeja ser desenvolvido ou, inclusive, optar pelo não desenvolvimento da atividade.

Cabe ressaltar ainda que a Organização Mundial de Turismo ([OMT], s.d.) entende que um dos ponto-chave é que seja assegurada as atividades econômicas a longo prazo. Não visa, portanto, o revisar e repensar da atividade turística ou que possa se averiguar que o melhor é que a mesma deixe de ser fomentada em algum momento. Outro ponto a se destacar é que ao se pensar a distribuição de renda, aponta ser mister a redução da pobreza.

É preciso ter em vista que o entendimento sobre pobreza segue uma lógica eurocêntrica. Exemplo disto seriam as comunidades campesinas e povos da floresta vinculados ao que se estabelece como pobreza. Neste caso, embasada em cálculos do Produto Interno Bruto (PIB) e a qualidade de vida entendidos desde a perspectiva do Índice de Desenvolvimento Humano (IDH), os quais são equivocados para a compreensão de qualidade de vida desses povos (que são, inclusive, exemplo prático de sociedade sustentável).

Por outro lado, tem-se a dominação do espaço por meio dos ajustes espaço-temporais que propiciam a reprodução e ampliação do capitalismo (Harvey, 2004), contribuindo para a destruição da base de subsistência e reprodução social e cultural dos povos tradicionais e indígenas (Limonad, 2013). Desse modo, a busca pelo crescimento econômico em prol "da nação", desestabiliza e compromete a vida de diversas comunidades.

Como mencionado no Relatório de Desenvolvimento Humano do Programa das Nações Unidas para o Desenvolvimento (PNUD) (2010) é possível verificar IDH 
elevados, mas em locais insustentáveis, não democráticos e não equitativos, assim como é possível ter um IDH baixo e ser relativamente sustentável, democrático e equitativo. Esse índice é pautado na saúde, na educação e nos rendimentos, mas desde a perspectiva de educação e saúde enquanto serviços ofertados pelo sistema.

Não se considera a educação informal, nem a saúde desde a perspectiva da medicina natural, por exemplo. Também não considera que é possível viver com qualidade sem receber rendimentos. 0 próprio PNUD (2010, p. 80) aponta que os povos indígenas "enfrentam frequentemente desvantagens estruturais e apresentam piores resultados de desenvolvimento humano em aspecto-chave".

Posto a noção de desenvolvimento sustentável, formas alternativas de turismo foram utilizadas para ligá-lo a uma ideia de sustentabilidade, conforme ressaltado por Butler (1999) e Mowforth \& Munt (2009). Butler (1999) chama a atenção ao fato que alguns dos maiores críticos do turismo de massa são defensores do desenvolvimento sustentável e de formas alternativas de turismo, na crença que o apoio a este fará com que os problemas do turismo massivo desapareçam. É uma forma de pensar equivocada, uma vez que todas as formas de turismo impactam de alguma forma. Assim como é ingênuo e prejudicial pensar que o turismo centrado na natureza seja automaticamente sustentável.

O problema principal do uso do termo "desenvolvimento sustentável" no contexto do turismo é que ao invés de assegurar a introdução contínua de formas de turismo em pequena escala e ambiental e culturalmente apropriadas, ele parece apenas representar perspectivas de como tornar o turismo de massa o mais sustentável possível (Butler, 1999).

Ou seja, ocorre o mesmo que acontece de forma geral com o desenvolvimento sustentável: sua utilização valida o crescimento econômico ao invés de promover uma ruptura ou mudança substancial no sistema hegemônico. Sobre essa "fetichização da sustentabilidade", Limonad (2013) destaca que ao mesmo tempo em que ela legitima propostas, lhes confere um caráter neutro e apolítico.

Por outro lado, iniciativas de turismo em pequena escala começaram a ser denominadas "sustentáveis" com o intuito de atrair o perfil de turista interessado neste modo de prática. Além do equívoco quanto ao uso do termo, as iniciativas em pequena escala caso sejam inadequadas à localidade ou mal operacionalizadas, podem impactar tanto quanto uma de grande escala (Butler, 1999).

Ademais, por ter emergido da preocupação global com o meio ambiente o desenvolvimento sustentável é quase invariavelmente reduzido e articulado em termos das questões ambientais. No caso do turismo, Butler (1999) ressalta que deveria estar claro para todos os envolvidos que a atividade, assim como a maior parte das formas de uso de recursos (se não todas), se relaciona tanto com o mundo físico quanto com as questões não físicas. Ou seja, o turismo impacta no meio físico, mas também sobre os âmbitos social e cultural.

Nesse sentido, observa-se um caso interessante de ambiguidade quanto ao desenvolvimento sustentável: ao entender que a sustentabilidade deve prever o benefício social do presente sem comprometer as gerações futuras, entende-se que as necessidades das populações sejam atendidas hoje.

Em adição, quando o Relatório Brundtland foi publicado, preocupou-se com a diminuição da pobreza econômica e distribuição equitativa da renda, conforme visto anteriormente. Soma-se a esse fato - agora especificamente no âmbito do turismo - que o turismo sustentável em parques (ou quaisquer outras áreas) 
deve ser pensado, especialmente, a partir da manutenção dos ecossistemas, mas também do bem-estar da população local (Butler, 1999).

Posto isso, destaca-se um caso debatido no Brasil no ano de 2017: a concessão de parques no estado de São Paulo e especificamente a sobreposição de quatro áreas com aldeias Guarani (Terra Indígena de Jaraguá, em São Paulo e Osasco; Aldeia Renascer Ywyty Guaçu, em Ubatuba; Aldeia Tekoha Paranapuã, em São Vicente; e Terra Indígena Pakurity, na Ilha do Cardoso), além de outras comunidades tradicionais, como quilombos.

A concessão foi aprovada a partir da Lei Estadual n.16.260/2016 e permite a exploração de 25 Unidades de Conservação (UCs), por setores econômicos como o extrativismo e o turismo, por um período de 30 anos (Lei n. 16.260, 2016).

Entre as contrapartidas exigidas pelo Estado, prevê que as empresas se comprometam a buscar "mecanismos de promoção do desenvolvimento sustentável das populações tradicionais existentes no interior das áreas concedidas e no seu entorno", incluindo no que tange às atividades turísticas (Lei n. 16.260, 2016). Posto isso, entende-se que o desenvolvimento sustentável estará vigente e tanto a natureza, quanto as populações residentes nessas áreas, em seus aspectos sociais, culturais e econômicos, serão protegidas.

Se analisada a Agenda 21 brasileira, verifica-se similaridade deste plano de ação e a lei supracitada. Dentre as ações imediatas propostas na Agenda 21 brasileira está a melhoria do uso das UCs já existentes, inclusive pela implementação do turismo (Ministério do Meio Ambiente [MMA] \& PNUD, 2002). A proposta está de acordo com o que, dentro das pesquisas em turismo, tem-se incentivado e entende que a implementação do turismo em áreas protegidas é sim uma atividade alternativa e importante para as comunidades locais.

No entanto, o turismo em UCs no Brasil vem sendo desenvolvido pelo Estado ou por via da concessão a empresas privadas, visando a geração de divisas, como pode ser verificado na publicação do Instituto Chico Mendes de Conservação da Biodiversidade (ICMBio) intitulada Contribuições do Turismo em Unidades de Conservação Federais para a Economia Brasileira - Efeitos dos Gastos dos Visitantes em 2015, onde o órgão destaca que, naquele ano, as UCs Federais receberam mais de 8 milhões de visitantes e gastaram $\mathrm{R} \$ 1,1$ bilhão nos municípios que dão acesso às áreas (Souza, Thapa, Rodrigues \& Imori, 2017). Além de outros impactos econômicos positivos, como empregos e renda. Conforme ressaltado no documento, no total, a cada R $\$ 1$ gasto em uma UC, foram gerados $\mathrm{R} \$ 7$ em benefícios econômicos para o país.

Outra ação imediata abordada na Agenda 21 brasileira e que vai ao encontro do exposto acima é "transformar o meio ambiente em área de negócios" (MMA \& PNUD, 2002, p. 17), uma visão pautada na economia verde, usando os ativos ambientais para incremento econômico. Segundo o MMA e PNUD (2002), para que essas ações e outras elencadas no documento sejam alcançadas são necessários três passos principais: negociação para administração de conflitos; pacto social, para o comprometimento de todos os atores; e escolha, para identificar entre os vários caminhos as melhores alternativas.

A partir dessa informação, entende-se que após um diagnóstico do campo, possíveis conflitos devem ser resolvidos por meio de um pacto entre os envolvidos, buscando um equilíbrio e, com isso, procurar as melhores alternativas para o local (dimensão ambiental) e para os envolvidos no conflito (âmbitos social, 
cultural e econômico). Novamente, embora tenha um caráter econômico sobressalente, a proposta parece pactuar com o desenvolvimento sustentável.

Se for pensado realmente o benefício social, a equidade, a distribuição justa de renda, o fortalecimento e ampla participação política e social e a proteção cultural, dentre outros aspectos preconizados pelo desenvolvimento sustentável e seus derivados, a exploração das UCs que o governo de São Paulo pretende privatizar deveriam ser concedidas às comunidades locais e não às empresas privadas.

0 que se percebe é que os passos pré-definidos na Agenda 21 brasileira, expostos acima, não foram cumpridos, tendo em vista que as comunidades não foram nem mesmo consultadas sobre a medida, muito menos ocorreu mediação de conflito ou busca por alternativas mais viáveis.

No que se refere ao caso do Pico do Jaraguá, Sansolo (2017 como citado em Adoue, 2017, s. p.) aponta que:

[...] na realidade, não se trata de conservação versus Terra Indígena, mas de privatização da paisagem. De fetichização do panorama do Pico do Jaraguá, sem qualquer transmissão de conteúdo sobre o significado da natureza local (geologia, geomorfologia, cobertura vegetal, etc.). Muito menos sobre o significado histórico do local, nem antes da colonização, nem depois. Havia uma grande diversidade de etnias indígenas no Planalto do Piratininga. A dinâmica da cidade nem de perto é abordada aos visitantes. 0 interesse é somente o de espetacularização do panorama (distinto de paisagem) sem qualquer significado geográfico. Usam dessa maneira a institucionalização da proteção da natureza como meio de enfraquecer a política territorial indigenista para, em seguida, tornar natureza e cultura em mercadorias.

Destarte, uma ação que pode ser entendida como benéfica para o turismo, que se utiliza inclusive de um discurso raso de desenvolvimento sustentável, em realidade acaba representando uma ação de desterritorialização, de exclusão social, de marginalização e desvalorização de povos indígenas e comunidades tradicionais. Assim como o exemplo citado acima, entende-se que o sustentável, para o turismo, se traduz em ações práticas visando questões ambientais - mas majoritariamente inseridas na perspectiva da economia verde -, excluindo o ser humano dessa cadeia de relações, como se o turismo não afetasse diretamente as sociedades, assim como ressaltado por Ramos (2005).

Nesse aspecto, assim como mencionado por Hunter (1997), por mais atraente que seja a noção de turismo sustentável, diversas questões precisam ser abordadas e debatidas. Esse pesquisador questiona sobre o que realmente significa, por exemplo, proteger os recursos naturais e interroga se essa proteção diz respeito à conservação ou à preservação e quais recursos exatamente seriam estes. São diversas lacunas que precisam ser pensadas para que o conceito tenha mais consistência. E é preciso agregar mais um questionamento: preservar/conservar recursos naturais para quem?

Destaca-se um caso emblemático no litoral do estado do Paraná, onde se localiza um dos mais importantes destinos turísticos do estado: a Ilha do Mel (Paranaguá). A maior parte da ilha é área de proteção ambiental, incluindo duas UCs de proteção integral: a Estação Ecológica (Esec) da Ilha do Mel e o Parque Estadual (PE) da Ilha do Mel, administradas pelo Instituto Ambiental do Paraná (IAP) desde 1982. 
A transformação de uma porção considerável da Ilha do Mel em área protegida envolveu todas as comunidades locais, no entanto, a mais afetada foi a comunidade da Ponta Oeste, devido à sua localização e à suscetibilidade de suas condições, visto que o local ficou completamente cercado pela Esec e pelo mar (Denkewicz et al., 2017).

A dimensão ambiental da sustentabilidade se destaca nesse aspecto, uma vez que as UCs protegem os "recursos" naturais para usufruto imediato e futuro. No entanto, as dimensões cultural e social do desenvolvimento sustentável são negligenciadas, uma vez que a comunidade supracitada vem sofrendo com as restrições ambientais, que fragilizam sua condição de comunidade tradicional pesqueira e impede o modo de vida tradicional e a própria permanência das pessoas no local. Denkewicz et al. (2017, p. 13) apontam que:

a pressão sobre os moradores da Ponta Oeste [...] se manifesta na forma de multas por crimes ambientais, baseadas na legislação de zoneamento ambiental, que é aplicada de forma mais severa, mesmo quando as proibições impossibilitem que os moradores consigam os recursos necessários para sua sobrevivência. Assim, tenta-se manter a comunidade no isolamento e no esquecimento, cercada por leis ambientais que restringem seus direitos sociais e culturais.

A comunidade da Ponta Oeste foi posta como invisível pela Prefeitura Municipal de Paranaguá, uma vez que em sua página eletrônica, mais especificamente no Guia turístico da Ilha do Mel, menciona-se a existência de cinco vilarejos, não sendo mencionada esta comunidade entre os mesmos (Paranaguá, s.d.).

Outro exemplo que demonstra que a ideia de desenvolvimento sustentável é ampla o suficiente para que se enquadre nela diversas formas de intervenção do espaço, consta nas "Estratégias Setoriais" da Agenda 21 brasileira, mais especificamente no que diz respeito ao subsetor de transportes de carga. Neste documento, um dos macro-objetivos do referido subsetor é "aprimoramento portuário institucional e legal para o desenvolvimento sustentável", sendo um dos objetivos específicos "desenvolver e implantar uma política nacional de conflitos de uso do litoral para áreas de turismo costeiro, e implantar terminais portuários" (MMA \& PNUD, 2000, p. 54).

Embora o documento se preocupe com os conflitos gerados pelo uso e apropriação do solo e com a questão da contaminação dos recursos hídricos, entende-se que o desenvolvimento sustentável não se alcança com a implantação de grandes obras de infraestrutura, que em diversos casos no Brasil vem desterritorializando comunidades e gerando os mais diversos conflitos e impactos socioambientais (Fundação Oswaldo Cruz [FIOCRUZ], s. d.).

Nesse sentido, indaga-se qual é a escala de análise quando se fala em desenvolvimento sustentável: estaria sendo pensada em escala local, municipal, estadual, nacional ou global? A sustentabilidade não seria alcançada a partir do desenvolvimento territorial? Em que medida o desenvolvimento sustentável, nesse caso, estaria preocupado com outras dimensões que não a econômica?

Novamente concorda-se com Ramos (2005, p. 73) quando este aponta que a:

[...] complexidade do fenômeno turístico não tem ultrapassado o campo do discurso, nem mesmo nas práticas da própria Organização Mundial do Turismo, que em 
seus eventos e encontros costuma reduzir o discurso da sustentabilidade ao "enriquecimento" das comunidades receptoras de turistas, sem necessariamente dimensionar os custos desse enriquecimento.

A essa afirmação cabe fazer uma ressalva: o enriquecimento do local/município/região é visado, uma vez que em inúmeros casos o benefício econômico não é realmente equitativo. Retoma-se então os questionamentos anteriormente levantados: desenvolvimento sustentável para quem, e a custo de quê?

Na questão dos portos, adentra-se a algo vislumbrado no setor do turismo incluindo dentro da academia - que são os projetos de revitalização de áreas portuárias e uso turístico dos portos, incluindo a construção de áreas para recepção de navios de cruzeiro, como é o caso do Porto de Paranaguá, no Paraná (Administração dos Portos de Paranaguá e Antonina [APPA], s.d.), que pretende estruturar um novo berço para navios de passageiros com terminal. Serão cerca de 300 mil metros quadrados para construção de uma área receptiva para turistas, ou seja, navios de cruzeiro.

Frente ao modelo desenvolvimentista e a seguinte onda neoliberal, o litoral do Brasil vem sendo explorado de forma insustentável, por vezes respaldada pelo setor do turismo. Basta acessar ao Mapa de Conflitos Envolvendo Injustiça Ambiental e Saúde do Brasil, organizado pela FIOCRUZ (s. d.) para perceber que os portos são responsáveis por diversos conflitos socioambientais, envolvendo, principalmente, comunidades tradicionais e indígenas.

0 setor do turismo pode se isentar de tais debates, sendo por vezes o mote para alterações no uso desses espaços? Qual o sentido de sustentabilidade no turismo, se por um lado preconiza-se a necessidade de "inserção" das comunidades locais na atividade e por outro, há conivência com despejo, desalojamento, desterritorialização, além de outros impactos sociais e culturais decorrentes desse processo?

Tem-se, desse modo, um exemplo do que ocorre nas estatísticas do turismo e no discurso oficial: concepções idealizadas dos benefícios gerados, mascarando ou minimizando impactos socioambientais e culturais (Irving, Bursztyn, Sancho \& Melo, 2005). Agrega-se a isto, a invisibilização de parte dos envolvidos no processo e a defesa de um projeto neoliberal que, não raramente, é enaltecido como sendo em benefício "da nação".

Os autores citados apontam que embora com esse panorama, existe uma direção possível que transcende os imediatismos políticos e busca consolidar a participação cidadã nas diversas escalas. A partir dessa participação é que o turismo pode se consolidar como um veículo de transformação social, para além das fronteiras políticas.

\section{CONSIDERAÇÕES FINAIS}

A busca por alternativas ao modelo de desenvolvimento hegemônico não é apenas importante, como necessária, visto a nocividade da forma como a busca pelo crescimento econômico - de poucos - tem colocado em risco a sociobiodiversidade global, além de contribuir para uma produção socioespacial desigual.

A noção de desenvolvimento atrelada apenas a uma perspectiva de crescimento econômico é insuficiente e precisa ser superada. Da mesma forma, no âmbito 
do turismo, faz-se necessário incentivar novas formas de praticar e desenvolver a atividade, com vistas romper sua relação histórica com o modelo hegemônico de produção e consumo. Mas isso não será suficiente se a discussão sobre sustentabilidade e a perspectiva de um turismo sustentável não ocorrerem de forma crítica, aprofundada e verdadeiramente orientada para além de um fundo econômico.

Com base neste contexto, o presente ensaio teórico buscou problematizar o modo como o campo do turismo tem se apropriado dessas noções. Isso porque, esse processo muitas vezes ocorre de modo acrítico, com o uso desses termos de forma genérica e esvaziada da complexidade de suas dimensões e implicações, inclusive sem um questionar acerca da viabilidade real da sustentabilidade da atividade turística, inclusive nas iniciativas e segmentos que são denominados "turismo sustentável".

É necessário diferenciar os conceitos de turismo sustentável e desenvolvimento sustentável do turismo, com maior atenção e reflexão sobre a viabilidade deste último. 0 turismo deve ser constante em uma localidade? Deve ou precisa ser desenvolvido "para sempre", após sua concepção? E se o turismo não for constante, isso seria um caso de "fracasso"? Essas reflexões precisam também estar presentes no pesquisar e estruturar do turismo. Como apontado anteriormente, é necessário que as comunidades locais possuam autonomia no delineamento do modelo a ser seguido ou mesmo no optar pelo não desenvolvimento (ou interrupção) da atividade.

Compreende-se que é imprescindível um aprofundamento crítico sobre o que consiste de fato um desenvolvimento sustentável e como este pode ser replicado ao contexto da atividade turística. Enquanto essas noções forem encaradas de forma acrítica, sem uma compreensão aprofundada sobre as diferentes abordagens nos campos social, cultural, ambiental e político e também considerando como paradigmas dominantes guiam as construções teóricas, os profissionais do turismo, em especial seus estudiosos, estarão presos às ideias incorretas a respeito do que a sustentabilidade realmente significa.

Por fim, mas não menos importante, faz-se mister desvincular a própria percepção de turismo apenas a uma lógica econômica - e inclusive do entendimento de que se trata somente de uma atividade econômica, marginalizando os debates acerca do turismo enquanto fenômeno social. Assim como ocorre com a discussão sobre desenvolvimento e sustentabilidade, ao se direcionar apenas a um contexto econômico, tende-se ao esvaziamento de significado e efetividade.

É preciso superar a ideia de que a dimensão econômica deve ser privilegiada, ampliando a percepção de que um desenvolvimento sustentável não deve desassociar o ser humano da natureza, como se não houvesse uma dialética, uma relação de retroalimentação entre os sistemas humanos e não humanos. Assimilando, assim, a sinergia entre as questões ambientais, sociais, econômicas, culturais e políticas.

A compreensão da atividade turística para além de sua esfera econômica é cogente tanto pela importância de não se condicionar e limitar o olhar cientifico sob essa perspectiva, quanto pela necessidade de que pesquisadores e planejadores não se isentem do debate e da responsabilidade do turismo por ações que podem ser consideradas contrárias aos ideais da sustentabilidade.

Destaca-se a urgência de uma reflexão sobre a essência e a complexidade das noções expressas no presente ensaio teórico para fortalecer outros modelos de 
turismo, que se contraponham ao modelo hegemônico e que sejam inclusivos, equitativos e com baixo impacto social, cultural e ambiental. Que façam jus ao conceito de sustentabilidade, como é o caso do Turismo de Base Comunitária (TBC), turismo comunitário, turismo de base familiar, entre outros modelos que se constituem alternativas ao desenvolvimento.

\section{REFERÊNCIAS}

Administração dos Portos de Paranaguá e Antonina - APPA (s.d.). Novos projetos. Recuperado em 10 nov.2019 de: <http://www.portosdoparana.pr.gov.br/modules/conteudo/conteudo. php?conteudo=159>.

Adoue, S. B. (2017, 25 de setembro). Terras Guarani no Estado de SP estão ameaçadas de privatização. Unesp Agência de Notícias Online. Recuperado em 10 nov. 2019 de: $<$ http://unan.unesp.br/destaques/29523/terras-guarani-no-estado-de-sp-estaoameacadas-de-privatizacao>.

Butler, R. W. (1999). Sustainable tourism: a state-of-the-art review. Tourism Geographies 1: 7-25. 10.1080/14616689908721291.

Cavalcanti, C. (2012). Sustentabilidade: mantra ou escolha moral? Uma abordagem ecológicoeconômica. Estudos Avançados Online 26 (74): 35-50. Recuperado em 10 nov. 2019 de: <https://doi.org/10.1590/S0103-40142012000100004>.

Coordenação de Aperfeiçoamento de Pessoal de Nível Superior - CAPES (s.d.). Portal de periódicos Recuperado em 10 nov. 2019 de: <http://www-periodicos-capes-gov-br.ez22. periodicos.capes.gov.br/>.

Corbari, S. D. (2017). Alternativas ao desenvolvimento, autonomia dos povos indígenas e limitações: o caso do turismo em terras indígenas. Revista Turismo Contemporâneo 5 (2): 301-322. Recuperado em 10 nov. 2019 de: <https://periodicos.ufrn.br/turismocontemporaneo/ article/view/12497>.

Denkewicz, P., Gonzaga, C. A. M., Grespan, T., Corbari, S. D., \& Vieira, R. dos S. (2017). Desenvolvimento, Unidades de Conservação e os conflitos socioambientais no litoral do Paraná. In Anais do Simpósio Brasileiro De Desenvolvimento Territorial Sustentável (p. 1542-1552). Universidade Federal do Paraná. Recuperado de: <http://https://drive. google.com/file/d/15potEWFjH5To29nAef_03HHxRqU0ORPb/view>.

Diegues, A. C. S. (1992). Desenvolvimento sustentado ou sociedades sustentáveis? Da crítica dos modelos aos novos paradigmas. São Paulo em Perspectiva 1 (2): 22-29. Recuperado em 10 nov. 2019 de: <http://www.michaeljonas.com.br/meu\%20trabalho/fca_grad/ Economia\%20II/Apo/Desenvolvimento\%20Sustentavel.pdf>.

Estades, N. P. (1999). El precio del ecosistema global: elementos para su interpretación. Comentário crítico do artigo de Constanza, R. d'A., d'Arge, R., Farber, S., Grasso, M., Hannon, B; Limburg, K., Naeem, S., O’Neill, R., Paruelo, J., Raskin, G. R., Sutton, P., \& Van den Belt, M. The value of the world's ecosystem services and natural capital. Nature, 387: 253-260.

Fundação Oswaldo Cruz - FIOCRUZ (s.d.). Mapa dos conflitos envolvendo injustiça ambiental e saúde no Brasil. Recuperado em 10 nov. 2019 de: <https://www.conflitoambiental.icict. fiocruz.br/index.php>.

Gudynas, E. (2012). Debates sobre el desarrollo y sus alternativas en América Latina: Una breve guía heterodoxa. In Lang, M.; Mokrani, D. Más allá del desarrollo (pp. 21-54). 1 Ed. Fundación Rosa Luxemburg/Abya Yala. 
Guimarães, R. P. \& Bezerra, J. (2011). Novas questões ou velhos problemas: a posição do Brasil na agenda internacional do meio ambiente. In Ferreira, L. da C. (Org.). A questão ambiental na América Latina (pp. 83-98). Editora da Unicamp.

Harvey, D. (2004). O novo imperialismo. (Trad. Adail Ubirajara Sobral e Maria Stela Gonçalves). Edições Loyola.

Hoeffel, J. L. de M., \& Reis, J. C. (2011). O conceito de sustentabilidade na teoria social latino-americana: uma análise preliminar. In Ferreira, L. F. da. A questão ambiental na América Latina (pp. 189-206). Editora da Unicamp.

Hunter, C. (1997). Sustainable tourism as an adaptive paradigm. Annals of Tourism Research 24 (4): 850-867. Recuperado em 10 nov. 2019 de: <https://doi.org/10.1016/S01607383(97)00036-4>.

Irving, M. de A., Bursztyn, I., Sancho, A. P., \& Melo, G. de M. (2005). Revisitando significados em sustentabilidade no planejamento turístico. Caderno Virtual de Turismo 5 (4): 1-7. Recuperado em 10 nov. 2019 de: <http://www.ivt.coppe.ufrj.br/caderno/index.php/ caderno/article/view/98>.

Latouche, S. (2007). Sobrevivir al desarrollo: de la descolonización del imaginario económico a la construcción de una sociedad alternativa. Icaria editorial. Colección Más Madera.

Layrargues, P. P. (1997). Do ecodesenvolvimento ao desenvolvimento sustentável: evolução de um conceito? Proposta 24 (71): 1-5.

Limonad, E. (2013). A insustentável natureza da sustentabilidade: da ambientalização do planejamento às cidades sustentáveis. Cadernos Metrópole 15 (29): 123-142. Recuperado em 10 nov. 2019 de: <https://revistas.pucsp.br/index.php/metropole/article/view/15819>.

Milani, C. R. S. (2008). Ecologia política, movimentos ambientalistas e contestação transnacional na América Latina. Caderno CRH 21 (53): 287-301. Recuperado em 10 nov. 2019 de: <http://dx.doi.org/10.1590/S0103-49792008000200007>.

Ministério do Meio Ambiente \& Programa das Nações Unidades para o Desenvolvimento MMA/PNUD (2000). Agenda 21 brasileira - bases para discussão.

Ministério do Meio Ambiente \& Programa das Nações Unidades para o Desenvolvimento MMA/PNUD (2002). Agenda 21 Brasileira - Resultado da Consulta Nacional.

Mowforth, M. \& Munt, I. (2009). Tourism and sustainability: development, globalisation and new tourism in the third world. $3 \mathrm{Ed}$. Routledge.

Organização das Nações Unidades - ONU (1987). Nosso futuro comum.

Organização Mundial de Turismo - OMT (s.d.). Sustainable Development of Tourism. http://sdt.unwto.org/es/content/definicion.

Prefeitura Municipal de Paranaguá (s.d.). Guia turístico: Ilha do Mel. Recuperado em 10 nov. 2019 de: <http://www.paranagua.pr.gov.br/conteudo/guia-turistico/ilha-do-mel>. Programa das Nações Unidas para o Desenvolvimento - PNUD (2010). Relatório de Desenvolvimento Humano 2010, edição do $20^{\circ}$ aniversário.

Publicações em Turismo (s.d.). Base de dados de livros e artigos em periódicos científicos de turismo. Recuperado em 10 nov. 2019 de: <http://www.publicacoesdeturismo.com. br/default.html>.

Ramos, S. P. (2005). Ensaio breve sobre um Turismo Insustentável. Revista Hospitalidade 2 (2): 69-86. Recuperado em 10 nov. 2019 de: < https://revhosp.org/hospitalidade/ article/view/222/238>.

Rodrigues, A. M. (1998). Produção e consumo do e no espaço: problemática ambiental urbana. HUCITEC. 
Rodrigues, A. M. (2006). Desenvolvimento sustentável: dos conflitos de classes para os conflitos de gerações. In Silva, J. B. da, Lima, L. C., \& Dantas, E. W. (Orgs.). Panorama da geografia brasileira II (pp. 77-100). Annablume.

Sachs, I. (2008). Desenvolvimento: includente, sustentável, sustentado. Garamond.

São Paulo Estado. (2016, 29 junho). Lei n. 16.260, de 29 de junho de 2016. Parecer no 847, de 2016, da Comissão de Justiça e Redação. Diário Oficial do Estado de São Paulo, 30 de jun., 126 (120). Recuperado em 10 nov. 2019 de: <http://dobuscadireta.imprensaoficial. com.br/default.aspx?DataPublicacao $=20160630 \&$ Caderno=DOE-I\&NumeroPagina $=1>$.

Souza, T. do V. S. B., Thapa, B., Rodrigues, C. G. de O., \& Imori, D. (2017). Contribuições do Turismo em Unidades de Conservação Federais para a economia brasileira: efeitos dos gastos dos visitantes em 2015. ICMBio. Recuperado em 10 nov. 2019 de: <http://www. icmbio.gov.br/portal/images/stories/comunicacao/publicacoes/publicacoes-diversas/ contribuicao_do_turismo_em_uc_federais_para_a_economia_brasileira.pdf.pdf>.

Recebido em :13/03/2018

Aprovado em: 25/05/2019

\section{CONTRIBUIÇÃO}

Sandra Dalila Corbari: Definição do problema de pesquisa e objetivos; desenvolvimento da proposição teórica; realização da revisão bibliográfica e fundamentação teórica; escolha dos procedimentos metodológicos; coleta de dados e análise de dados; realização de cálculos e projeções; revisão crítica do manuscrito; redação do manuscrito; adequação do manuscrito às normas da RTA.

Marina Rossi Ferreira: Definição do problema de pesquisa e objetivos; desenvolvimento da proposição teórica; realização da revisão bibliográfica e fundamentação teórica; escolha dos procedimentos metodológicos; coleta de dados e análise de dados; realização de cálculos e projeções; revisão crítica do manuscrito; redação do manuscrito; adequação do manuscrito às normas da RTA. 